\title{
A Hybrid Method to Deal with Aleatory and Epistemic Uncertainty in Risk Assessment
}

\author{
Palash Dutta \\ Dept. Of Mathematics \\ Dibrugarh University \\ Dibrugarh,-786004, India
}

\author{
Tazid Ali \\ Dept. Of Mathematics \\ Dibrugarh University \\ Dibrugarh,-786004, India
}

\begin{abstract}
Risk assessment is an important and significant aid in the decision making process. Risk assessment is performed using 'model' and a model is a function of parameters which are usually affected by uncertainty. Some model parameters are affected by aleatory uncertainty and some others are affected by epistemic uncertainty. In this paper we propose a hybrid method to deal with propagation of both kinds of uncertainty within the same computation of risk.
\end{abstract}

\section{Keywords}

Uncertainty, Risk Assessment, Monte Carlo simulation, Probability Theory, Possibility Theory

\section{Introduction}

Risk assessment is an important and popular aid in the decision making process. The aim of risk assessment [10] is to estimate the severity and likelihood of harm to human health from exposure to a substance or activity that under plausible circumstances can cause to human health. The assessment is performed using model and a model is a function of parameters which are usually affected by aleatory and epistemic uncertainty. Uncertainties have different representations viz. probabilistic and possibilistic. Many researchers have addressed uncertainty in risk assessment using probability theory. For example Labieniec , Dzombak and Siegris [15], Maxwell, Pelmulder, Tompson, and Kastenberg [17], Maxwell and Kastenberg [18], Prado, Draper, Saltelli, Pereira, Mendes, Eguilior, Cheal and Tarantola [16], Ma, Wu and Ton [12, 13] presented application of probability theory to human health risk assessment. But probability theory intended only for aleatory uncertainty and it is inappropriate to represent epistemic uncertainty. To overcome this limitation of probability theory Zadeh in 1965 introduced fuzzy set theory. Dou, Woldt, Bogardi, Dahab [7], Bardossy, Bronstert and Merz [1] and different researchers presented applications of possibility theory to the environment problems. Aleatory uncertainty arises due to inherent variability, natural stochasticity, environmental or structural variation across space or through time, manufacturing or genetic heterogeneity among components or individuals, and Varity of others sources of randomness. On the other hand epistemic uncertainty arises due to the insufficient knowledge about the world, which includes small sample sizes, detection limits, imperfections in scientific understanding etc. In risk assessment model parameters are usually affected either by aleatory uncertainty or by epistemic uncertainty. A few researchers have addressed the issue of combining probabilistic and possibilistic representation of aleatory and epistemic uncertainty respectively within the same computation of risk. For example, Baudrit, Dubois, Fargier [2], [3], Baudrit, Dubois [4], Guyonnet, Bourgine, Dubois, Fargier, Côme and Chilès [8], Guyonnet, Côme, Perrochet, Parriaux [9], kentel and Aral [10] have proposed hybrid method for join handling of probability and possibility distributions. The hybrid method proposed in [8] combines the random sampling of probability distribution functions (PDFs) with fuzzy interval analysis on the $\alpha$-cuts. In order to compare random fuzzy set to a tolerance threshold Guyonnet, Bourgine, Dubois, Fargier, Côme and Chilès [8] performed a post-processing of this result. Baudrit, Dubois, Guyonnet and Fargier [5] laid bare a shortcoming of this post-processing method. In [5] authors showed how the theory of evidence, also called theory of Dempster-Shafer (or theory of belief functions; Shafer, 1976) could provide a simple and rigorous answer to the problem of summarizing the results of the hybrid computation for comparison with a tolerance threshold. In the hybrid approach proposed in [10] combined utilization of fuzzy and random variables produces membership functions of risk to individuals at different fractiles of risk as well as probability distributions of risk for various alpha-cut levels of the membership function.

In this paper we propose a hybrid approach for combining probability and possibility distribution functions within the same computation of risk. We used both Monte Carlo simulation and possibility theory in our method in which the interval arithmetic proposed by Ganesan and Veeramani [14] is taken to perform interval operation. Further we assume independency between the parameters.

\section{PROBABILITY THEORY}

Probability theory frequently used in uncertainty analysis. If parameters used in prescribed models are random in nature and followed well define distribution, then probabilistic methods are most suitable and well accepted approach for risk assessment.

A random variable is a variable in a study in which subjects are randomly selected. Let $\mathrm{X}$ be a discrete random variable.

A probability mass function is a function such that

(i) $f\left(x_{i}\right) \geq 0$, (ii) $\sum_{i=1}^{n} f\left(x_{i}\right)=1$, (iii) $f\left(x_{i}\right)=p\left(x=x_{i}\right)$

The cumulative distribution function of a discrete random variable $\mathrm{X}$, denoted as $\mathrm{F}(\mathrm{x})$ is

$$
F(x)=P(X \leq x)=\sum_{x \leq x_{i}} f\left(x_{i}\right)
$$


Let $\mathrm{X}$ be a continuous random variable. A probability density function of $\mathrm{X}$ is a non-negative function $f$, which satisfies

$$
P(X \in B)=\int_{B} f(x) d x
$$

for every subset $B$ of the real line.

As $\mathrm{X}$ must assume some value, $\mathrm{f}$ must satisfy

$$
P\left(X \in(-\infty, \infty)=\int_{-\infty}^{\infty} f(x) d x=1\right.
$$

This means the entire area under the graph of the PDF must be equal to unit.

In particular, the probability that the value of $X$ falls within an interval $[a, b]$ is

$$
p(a \leq X \leq b)=\int_{a}^{b} f(x) d x
$$

The CDF of a continuous random variable $\mathrm{X}$ is

$$
F(x)=P(X \leq x)=\int_{-\infty}^{x} f(x) d x
$$

$\forall A, B$ we have, $P(A \cup B)=P(A)+P(B)-P(P \cap B)$

\section{POSSIBILITY THEORY}

Possibility theory normally associated with some fuzziness, either in the background knowledge on which possibility is based or in the set for which possibility is asserted. This constitute a method of formalizing non- probabilistic uncertainties on events i.e., a mean of assessing to what extent the occurrence of an event is possible and to what extent we are certain of its occurrence, without knowing the evaluation of the possibility of its occurrence.

A possibility distribution [6], denoted by $\pi$, here is a mapping from the real line to the unit interval, unimodal and upper semicontinuous. A possibility distribution describe the more or less plausible values of some uncertain variable $X$. Possibility theory provides two evaluations of the likelihood of an event, for instance that the value of a real variable $X$ should lie within a certain interval: possibility $\Pi$ and the necessity $N$. Possibility measure $\Pi$ and necessity measure $N$ are define

$$
\begin{gathered}
\Pi(A)=\sup _{x \in A} \pi(x) \\
N(A)=1-\pi\left(A^{D}\right),
\end{gathered}
$$

$\mathrm{A}^{\mathrm{c}}$ is the complement of $\mathrm{A}$.

$\prod$ Satisfies the following conditions

$$
\begin{aligned}
& \Pi(A \cup B)=\max (\Pi(A), \Pi(B)), \text { for all } A, B \subseteq R \\
& \Pi(A \cap B)=\min (\Pi(A), \Pi(B)), \text { for all } A_{,} B \subseteq R
\end{aligned}
$$

For triangular (trapezoidal) fuzzy numbers, possibility and necessity measures are straight lines. For example, if a continuous possibility distribution is a triangular fuzzy number say, $[\mathrm{a}, \mathrm{b}, \mathrm{c}]$ then possibility measure is given by $\frac{x-a}{b-a}, a \leq x \leq b$ and necessity measure is given by $\frac{x-b}{c-b}, b \leq x \leq c$.
In particular, consider a fuzzy number $A=[10,20,30]$. Then the possibility measure of the fuzzy number $\mathrm{A}$ is $\frac{x-10}{10}, 10 \leq x \leq 20$ and necessity measure of the fuzzy number $\mathrm{A}$ is $\frac{x-20}{10}, 20 \leq x \leq 30$. Which are depicted below:

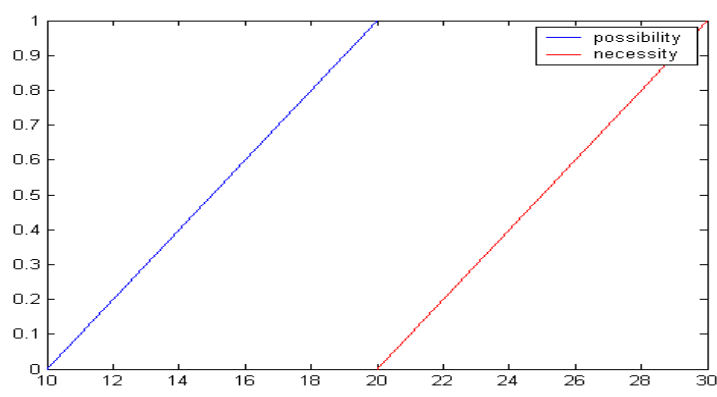

Figure 1: Possibility and necessity measure of the fuzzy number A

\section{1: Sampling Technique for Possibility Theory:}

Sampling technique to generate random numbers generally used in probabilistic method can also be used for possibility theory. Here, uniformly distributed random numbers between 0 and 1 are generated. Random variables of given uncertainty are generated by equating these numbers to necessity function and possibility function. Two numbers are generated in this process, one corresponding to necessity function and the other corresponding to the possibility function. This process is repeated for all the uncertainty variables present in the model.

For a uniformly distributed random number $\mathrm{u}$ the uncertain variable $x_{n}$ having necessity function $\operatorname{Nec}\left(x_{n}\right)$ and uncertainty variable $x_{p}$ having possibility function $\operatorname{Pos}\left(x_{p}\right)$ are obtained as

$x_{n}=\operatorname{Nec}^{-1}(u)$ and $x_{p}=\operatorname{Pos}^{-1}(u)$.

For example, for the fuzzy number $A=[10,20,30]$ the possibility measure and necessity measure are depicted in figure 1 . Now, for the uniformly generated random number say 0.6 , the value of the random variable is 26 for the necessity measure and 16 for the possibility measure.

Let $M=g\left(F_{1}, F_{2} \ldots, F_{m}\right)$ be a model having $m$ fuzzy numbers $F_{1}, F_{2} \ldots, F_{m}$. Each fuzzy number $F_{i}$ will give a necessity measure $F_{i n}$ and a possibility measure $F_{i p}$. Let $\mathrm{M}_{\mathrm{n}}$ and $M_{p}$ will be the values of $\mathrm{M}$ for a particular simulation, i.e.,

$M_{n}=g\left(F_{l n}^{\prime}, F_{2 n}^{\prime} \ldots, F_{m n}^{\prime}\right)$ and $M_{p}=g\left(F_{1 p}^{\prime}, F_{2 p}^{\prime} \ldots, F_{m p}^{\prime}\right)$ , where $F_{l n}^{\prime}, F_{2 n}^{\prime} \ldots, F_{m n}^{\prime}\left(F_{1 p}^{\prime}, F_{2 p}^{\prime} \ldots, F_{m p}^{\prime}\right)$ denote values for a particular simulation of $F_{l n}, F_{2 n} \ldots, F_{m n}\left(F_{l p}, F_{2 p} \ldots\right.$, $\left.F_{m p}\right)$.

\section{INTERVAL ARITHMETIC-A NEW APPROACH:}

In [14], Ganesan and Veeramani proposed a new interval arithmetic approach on $\boldsymbol{R}$ based on mid-point of interval. The approach is summarized below: 
For $\quad x=\left[x_{1}, x_{2}\right], y=\left[y_{1}, y_{2}\right] \in R \quad$ and $\quad$ for $* \in\{+,-, \times, \div\}$, they define a new type of binary operation as:

$x * y=[m(x) * m(y)-k, m(x) * m(y)+k]$, where

$m(x)$ and $m(y)$ are the mid-point of the intervals $x$ and $y$ respectively. Also where $k=\min \{(m(x) * m(y))-\alpha, \beta-(m(x) * m(y))\}$, $\alpha$ and $\beta$ are the end points of the interval $x \square y$ under the existing interval arithmetic. In particular

(i) Addition:

$x+y=\left[x_{1}, x_{2}\right]+\left[y_{1}, y_{2}\right]=[m(x)+m(y)-k, m(x)+m(y)+k]$, where $k=\left\{\left(y_{2}+x_{2}\right)-\left(y_{1}+x_{1}\right)\right\} / 2$.

(ii) Subtraction:

$x-y=\left[x_{1}, x_{2}\right]-\left[y_{1}, y_{2}\right]=[m(x)-m(y)-k, m(x)-m(y)+k]$, where $k=\left\{\left(y_{2}+x_{2}\right)-\left(y_{1}+x_{1}\right)\right\} / 2$.

(iii) Multiplication:

$x . y=x y=\left[x_{1}, x_{2}\right]\left[y_{1}, y_{2}\right]=[m(x) m(y)-k, m(x) m(y)+k]$,

where

$k=\min \{(m(x) m(y))-\alpha, \beta-(m(x) m(y))\}$,

$\alpha=\min \left\{x_{1} y_{1}, x_{1} y_{2}, x_{2} y_{1}, x_{2} y_{2}\right\}$ and

$\beta=\max \left\{x_{1} y_{1}, x_{1} y_{2}, x_{2} y_{1}, x_{2} y_{2}\right\}$.

(iv) Division:

$1 \div x=1 / x=1 /\left[x_{1}, x_{2}\right]=[1 / m(x)-k, 1 / m(x)+k]$,

where

$k=\min \left\{1 / x_{2}\left(\left(x_{2}-x_{1}\right) /\left(x_{2}+x_{1}\right)\right), 1 / x_{1}\left(\left(x_{2}-x_{1}\right) /\left(x_{2}+x_{1}\right)\right)\right\}$ and $0 \notin\left[x_{1}, x_{2}\right]$.

From (iii) it is clear that $\lambda x=\left[\lambda x_{1}, \lambda x_{2}\right]$, for $\lambda \geq 0$ and $\left[\lambda x_{2}, \lambda x_{1}\right]$, for $\lambda<0$.

\section{PROPOSED HYBRID APPROACH:}

Consider a model

$$
M=g\left(P_{l}, P_{2} \ldots P_{m}, F_{l}, F_{2} \ldots, F_{n}\right)
$$

which is a function of parameters where representations of some parameters are probabilistic and some parameters are possibilistic (Fuzzy number). Suppose $P_{l}, P_{2} \ldots P_{m}$ are $m$ parameters presented by probabilistic distributions and $F_{1}, F_{2}$. .., $F_{n}$ are $n$ parameters presented by possibilistic distributions (Fuzzy numbers).
The approach is explained below:

1. Generate $m$ number of uniformly distributed random numbers from $[0,1]$ and perform Monte Carlo simulation to obtain random numbers by sampling probability distribution.

2. Consider the possibility distribution $f: \mathrm{X} \rightarrow[0,1]$ (i.e., fuzzy numbers). Then, we use possibility measure and necessity measure defined as

$$
\begin{aligned}
& \operatorname{pos}(A)=\sup _{x \in A} f(x) \text { and } \\
& \operatorname{Nec}(A)=1-\operatorname{pos}\left(A^{c}\right)
\end{aligned}
$$

to obtain upper and lower probability.

3. Possibilistic Sampling: Generate $n$ numbers of uniformly distributed random numbers from $[0,1]$ and perform Monte Carlo simulation to obtain random numbers by sampling possibility distribution. Here we will get $n$ numbers of close intervals i.e., $2 \mathrm{n}$ numbers of random numbers will be generated ( $\mathrm{n}$ for possibility measure and $\mathrm{n}$ for necessity measure)

4. Assign all $m$ random numbers and $n$ closed intervals in the model $M$ and perform (whatever) arithmetic operation between random numbers and closed intervals. It will produce $\mathrm{n}$ numbers of closed intervals and thereafter perform arithmetic operation between the close intervals using $\mathrm{K}$. Ganesan et al Interval Arithmetic. Output will be a single closed interval.

5. Repeat step 1 to step $4 \mathrm{~N}$ times. So, we will have $\mathrm{N}$ numbers of close intervals.

6. Consider $M_{1}$ and $M_{2}$, the collections of all initial and end points of the resulting intervals respectively

7. Cdf plot of $M_{I}$ and $M_{2}$, which will give the upper probability and lower probability respectively.

\section{CASE STUDY:}

To demonstrate and make use of the proposed hybrid method a hypothetical case study for non-cancer risk assessment is presented here. As due to the discharge of produce water into the sea a lot of organic and inorganic pollutants (however, in this example we consider only the heavy metal arsenic (As) because of its toxicity and high concentration in produced water.) release into the water and which are harmful to the aquatic organism. Therefore human being may be affected by ingestion of such contaminated aquatic organism. An evaluation is necessary to determine the possible impact such substances may have on human health and ecology. For this purpose, risk assessment is performed to quantify the potential detriment to human and evaluate the effectiveness of proposed remediation measures.

The general form of a comprehensive food chain risk assessment model as provided by EPA, 2001 [11] is follows

$$
C D I=\frac{C_{f} \times F I R \times F R \times E F \times E D \times C F}{B W \times A T}
$$

Where CID = Chronic daily intake $(\mathrm{mg} / \mathrm{kg}$-day), FIR $=$ fish ingestion rate $(\mathrm{g} /$ day), $\mathrm{FR}=$ fraction of fish from contaminated source, $\mathrm{EF}=$ exposure frequency (day/year), ED $=$ exposure duration (years), $\mathrm{CF}=$ conversion factor $\left(=10^{-9}\right)$, $\mathrm{BW}=$ body weight $(\mathrm{kg}), \mathrm{AT}=$ averaging time (days) and $\mathrm{C}_{\mathrm{f}}=$ 
chemical concentration of fish tissue $(\mathrm{mg} / \mathrm{kg})$. The chemical concentration in fish tissue $\left(\mathrm{C}_{\mathrm{f}}\right)$ can be computed as

$$
C_{f}=P E C \times B C F
$$

Where PEC $=$ predicted environmental concentration $(\mathrm{mg} / \mathrm{l})$ and $\mathrm{BCF}$ is the chemical bioaccumulation factor in fish $(1 / \mathrm{kg})$. The non-cancer risk model for fish ingestion is expressed as:

$$
\text { Risk }_{\text {non-cancer }}=\frac{C D I}{R f d}
$$

Where, $R f d$ is the reference dose

Here, we will consider three fuzzy scenarios.

\subsection{Scenario1:}

In this scenario, representation of the parameters predicted environmental concentration (PEC), chemical bioaccumulation factors (BCF) are considered to be fuzzy number while body weight (BW) and fish ingestion rate (FIR) are taken as normal probability distribution and other parameters are taken to be constant. Values of the parameters for the calculation of non-cancer risk are given in the table 1 .

\begin{tabular}{|c|c|c|c|}
\hline Parameter & Units & $\begin{array}{l}\text { Type of } \\
\text { Variable }\end{array}$ & Value/distribution \\
\hline $\begin{array}{c}\text { Average } \\
\text { Time (AT) }\end{array}$ & Days & Constant & 25550 \\
\hline $\begin{array}{c}\text { Body Weight } \\
\text { (BW) }\end{array}$ & $\mathrm{Kg}$ & Probabilistic & $\operatorname{Normal}(70,1.945)$ \\
\hline $\begin{array}{c}\text { Exposure } \\
\text { Duration } \\
\text { (ED) }\end{array}$ & Years & Constant & 30 \\
\hline $\begin{array}{l}\text { Exposure } \\
\text { frequency } \\
(\mathrm{EF})\end{array}$ & Days/year & Constant & 350 \\
\hline $\begin{array}{c}\text { Fraction of } \\
\text { contaminated } \\
\text { Fish (FR) }\end{array}$ & - & Constant & 0.5 \\
\hline $\begin{array}{c}\text { Fish } \\
\text { Ingestion } \\
\text { Rate (FIR) }\end{array}$ & g/day & Probabilistic & $\operatorname{Normal}(170,1.941)$ \\
\hline $\begin{array}{l}\text { Conversion } \\
\text { Factor }(\mathrm{CF})\end{array}$ & - & Constant & $1 \mathrm{E}-09$ \\
\hline PEC for As & $\mathrm{ug} / \mathrm{l}$ & Fuzzy & {$[1,5,9]$} \\
\hline $\mathrm{BCF}$ for As & $1 / \mathrm{kg}$ & Fuzzy & {$[25,45,65]$} \\
\hline $\begin{array}{l}\text { Oral Rfd for } \\
\text { As }\end{array}$ & mg/(kg.day) & Constant & $3.0 \mathrm{E}-04$ \\
\hline
\end{tabular}

Table 1: Parameters used in the risk assessment

The results of the non-cancer human health risk assessment using equation (3) of scenario1 are depicted in figure (2).

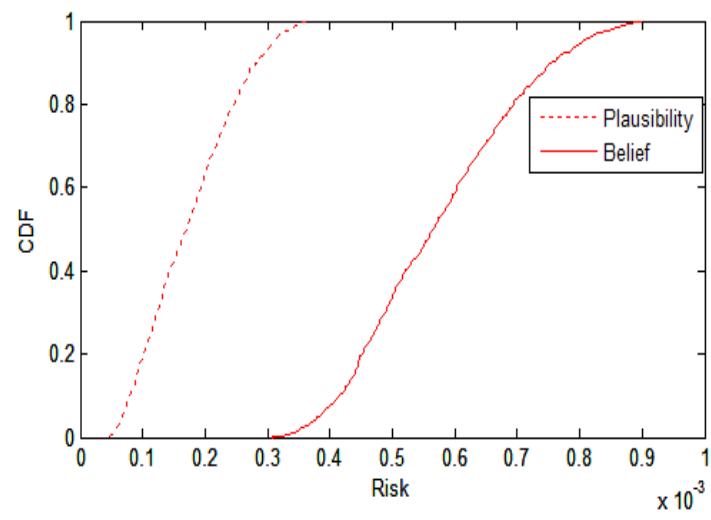

Fig 2: Non-cancer human health risk

\subsection{Scenario 2:}

In this scenario, representation of the parameters chemical bioaccumulation factor $(\mathrm{BCF})$ and reference dose (Rfd) are considered to be fuzzy number while the representation of the parameters body weight $(\mathrm{BW})$ and fish ingestion rate (FIR) are taken as probabilistic and other parameters are taken to be constant. Values of the parameters for the calculation of noncancer risk are given in the table 2 .

\begin{tabular}{|c|c|c|c|}
\hline Parameter & Units & $\begin{array}{l}\text { Type of } \\
\text { variable }\end{array}$ & Value/distribution \\
\hline $\begin{array}{c}\text { Average } \\
\text { Time (AT) }\end{array}$ & Days & constant & 25550 \\
\hline $\begin{array}{l}\text { Body Weight } \\
\text { (BW) }\end{array}$ & $\mathrm{Kg}$ & Probabilistic & $\begin{array}{c}\text { Normal( } 70, \\
1.945)\end{array}$ \\
\hline $\begin{array}{c}\text { Exposure } \\
\text { Duration } \\
\text { (ED) }\end{array}$ & Years & constant & 30 \\
\hline $\begin{array}{l}\text { Exposure } \\
\text { frequency } \\
\quad(\mathrm{EF})\end{array}$ & Days/year & constant & 350 \\
\hline $\begin{array}{c}\text { Fraction of } \\
\text { contaminated } \\
\text { Fish (FR) }\end{array}$ & - & constant & 0.5 \\
\hline $\begin{array}{c}\text { Fish } \\
\text { Ingestion } \\
\text { Rate (FIR) }\end{array}$ & g/day & Probabilistic & $\begin{array}{c}\text { Normal }(170, \\
1.941)\end{array}$ \\
\hline $\begin{array}{l}\text { Conversion } \\
\text { Factor }(\mathrm{CF})\end{array}$ & - & constant & 1E-09 \\
\hline PEC for As & $\mathrm{ug} / \mathrm{l}$ & constant & 5 \\
\hline $\mathrm{BCF}$ for As & $1 / \mathrm{kg}$ & Fuzzy & {$[25,45,65]$} \\
\hline $\begin{array}{l}\text { Oral Rfd for } \\
\text { As }\end{array}$ & mg/(kg.day) & Fuzzy & $\begin{array}{c}{[1.0 \mathrm{E}-04,3.0 \mathrm{E}-} \\
04,5.0 \mathrm{E}-04]\end{array}$ \\
\hline
\end{tabular}

Table2: Parameter values used in the risk assessment 
The results of the non-cancer human risk assessment using (3)

of scenario 2 is depicted in figure (3).

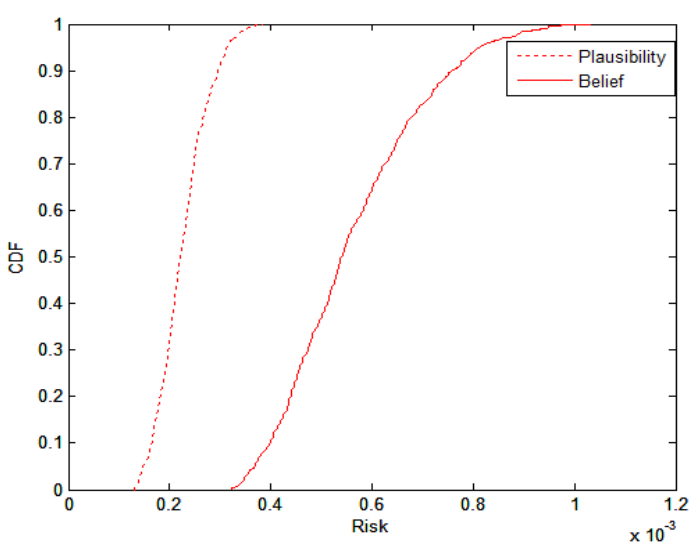

Fig 3: Non-cancer human health risk

\subsection{Scenario 3:}

In this scenario, representation of the parameters predicted environmental concentration (PEC), chemical bioaccumulation factor $(\mathrm{BCF})$ and reference dose (Rfd) are considered to be fuzzy number and other parameters are taken to be constant. Values of the parameters for the calculation of non-cancer human health risk are given in the table 3 .

Table3: Parameter values used in the risk assessment

\begin{tabular}{|c|c|c|c|}
\hline Parameter & Units & $\begin{array}{c}\text { Type of } \\
\text { variable }\end{array}$ & Value/distribution \\
\hline $\begin{array}{c}\text { Average } \\
\text { Time (AT) }\end{array}$ & Days & constant & 25550 \\
\hline $\begin{array}{c}\text { Body Weight } \\
\text { (BW) }\end{array}$ & $\mathrm{Kg}$ & Probabilistic & $\begin{array}{c}\text { Normal(70, } \\
1.945)\end{array}$ \\
\hline $\begin{array}{c}\text { Exposure } \\
\text { Duration } \\
\text { (ED) }\end{array}$ & Years & constant & 30 \\
\hline $\begin{array}{c}\text { Exposure } \\
\text { frequency } \\
\text { EF) }\end{array}$ & Days/year & constant & 350 \\
\hline $\begin{array}{l}\text { Fraction of } \\
\text { contaminated } \\
\text { Fish (FR) }\end{array}$ & - & constant & 0.5 \\
\hline $\begin{array}{l}\text { Fish } \\
\text { Ingestion } \\
\text { Rate FIR) }\end{array}$ & $\mathrm{g} / \mathrm{day}$ & Probabilistic & Normal(170, \\
\hline $\begin{array}{l}\text { Conversion } \\
\text { Factor (CF) }\end{array}$ & - & constant & $1.941)$ \\
\hline PEC for As & ug/l & constant & {$[1,5,9]$} \\
\hline BCF for As & $1 / \mathrm{kg}$ & Fuzzy & {$[35,45,65]$} \\
\hline $\begin{array}{c}\text { Oral Rfd for } \\
\text { As }\end{array}$ & $\mathrm{mg} /(\mathrm{kg}$.day) & Fuzzy & $\begin{array}{c}{[1.0 \mathrm{E}-04,3.0 \mathrm{E}-} \\
04,5.0 \mathrm{E}-04]\end{array}$ \\
\hline
\end{tabular}

The results of the non-cancer human risk assessment using (3) of scenario 3 is depicted in figure (4).

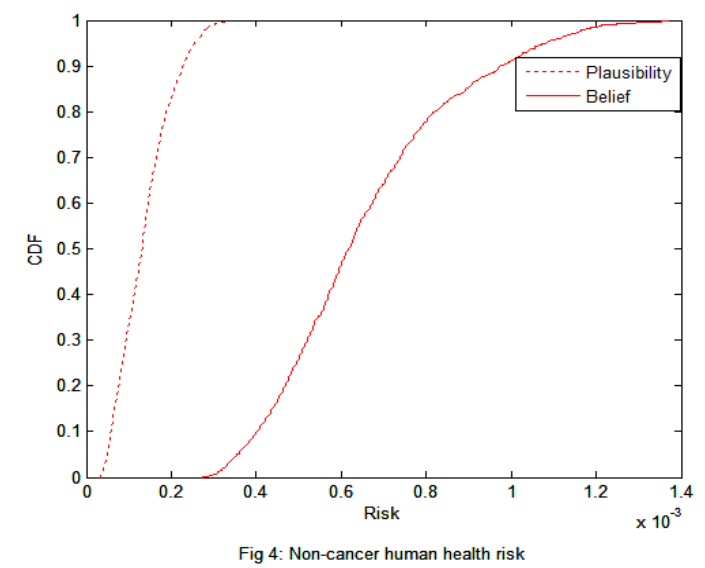

In this study, in each scenario representation of some parameters are aleatory nature and some are epistemic nature. Using our proposed method to deal with both type uncertainty natures in the risk assessment we have the result in the form of belief and plausibility. From these two belief and plausibility, risk at different fractiles ([17], [10]) can be calculated and which are obtained in the form of close intervals. For instance, for scenario1, at $95^{\text {th }}$ fractile, the risk value lies between $0.3098 \mathrm{e}-03$ and $0.8047 \mathrm{e}-03$; at $85^{\text {th }}$ fractile, the risk value lies between $0.2624 \mathrm{e}-03$ and $0.7247 \mathrm{e}-03$; at $80^{\text {th }}$ fractile, the risk value belongs to [0.2464e-03, 0.6938e-03]. Similarly for scenario 2 , at $95^{\text {th }}, 85^{\text {th }}$ and $80^{\text {th }}$ fractiles, risk values belong to $[0.3145 \mathrm{e}-03,0.8142 \mathrm{e}-03],[0.2803 \mathrm{e}-03,0.7182 \mathrm{e}-03]$ and $[0.2665 \mathrm{e}-03,0.679 \mathrm{e}-03]$ respectively. Also risk at those fractiles for scenario 3 will be respectively [0.2539e-03, $1.084 \mathrm{e}-03], \quad[0.207 \mathrm{e}-03,0.8947 \mathrm{e}-03]$ and $[0.1878 \mathrm{e}-03$, $0.8209 \mathrm{e}-03]$.

Instead of interval arithmetic [14] if we consider vertex method to combine intervals in the proposed hybrid method the results contains more imprecision than the proposed method and also results tally with [6]. The results of the noncancer human risk assessment, applying vertex method in the proposed hybrid method and the superimposition of both the methods of scenario1, 2 and 3 are depicted in figure 5-figure 10.

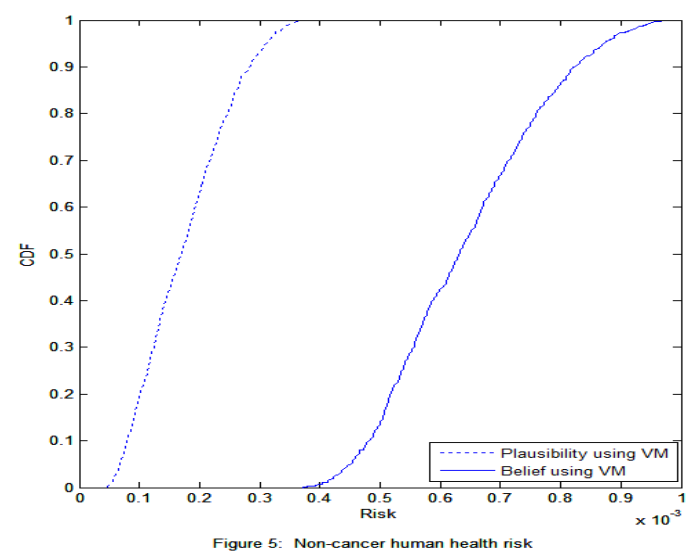



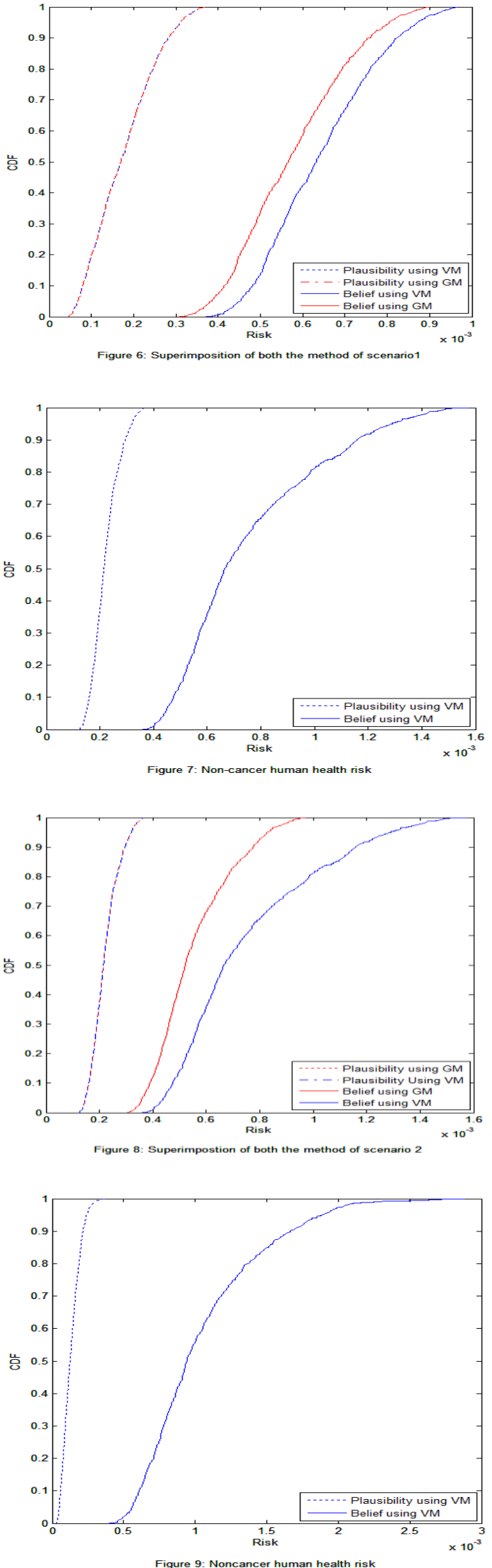

Figure 9: Noncancer human health risk

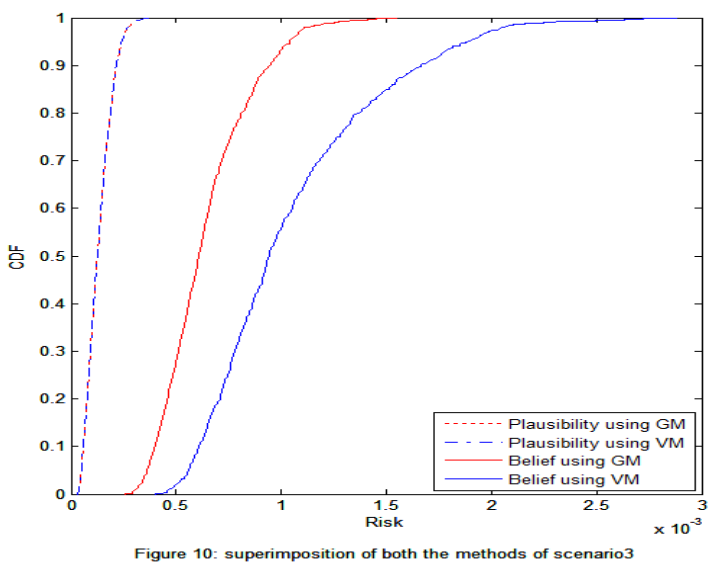

Here, for scenario1, at $95^{\text {th }}$ fractile, the risk value ranges from $0.3098 \mathrm{e}-03$ and $0.8716 \mathrm{e}-03$; at $85^{\text {th }}$ fractile, the risk value lies between $0.2624 \mathrm{e}-03$ and $0.7919 \mathrm{e}-03$; at $80^{\text {th }}$ fractile, the risk value belongs to [0.2464e-03, 0.7600e-03]. Similarly for scenario2, at $95^{\text {th }}, 85^{\text {th }}$ and $80^{\text {th }}$ fractiles, risk values belong to $[0.3145 \mathrm{e}-03,1.289 \mathrm{e}-03],[0.2803 \mathrm{e}-03,1.086 \mathrm{e}-03]$ and $[0.2665 \mathrm{e}-03,0.9687 \mathrm{e}-03]$ respectively. Also risk at those fractiles for scenario 3 will be respectively [0.2539e- 03 , $1.892 \mathrm{e}-03],[0.207 \mathrm{e}-03,1.514 \mathrm{e}-03]$ and $[0.1878 \mathrm{e}-03,1.375 \mathrm{e}-$ 03]. In this study, we have seen that our proposed approach gives more precise result than the other. Also graphical representations of the results reflect the same situation.

\section{CONCLUSION}

In risk assessment, it is most important to know the nature of all available information, data or model parameters. More often, it is seen that available information is interpreted in probabilistic sense because probability theory is a very strong and well established mathematical tool to deal with aleatory uncertainty. However, it is clear that not all available information, data or model parameters are affected by aleatory uncertainty (i.e., nature of the data, information or parameters are random) and can be handled by traditional probability theory. Imprecision may occur due to scarce or incomplete information or data, measurement error or data obtain from expert judgment or subjective interpretation of available data or information. Thus, model parameters, data may be affected by epistemic uncertainty. Fuzzy set theory or possibility theory should be explored to handle this type of uncertainty. Sometimes, it is also seen that some model parameters are affected by aleatory uncertainty and some parameters are affected by epistemic uncertainty. For this purpose, in this study, we proposed a hybrid approach to combine both modes of representations of uncertainty by considering independency between the parameters. In our approach first uniformly distributed random numbers are generated and Monte Carlo simulation is performed for probability distribution to obtain random numbers. Then we consider the possibility distributions i.e., fuzzy numbers and use the possibility and necessity measures to obtain upper and lower probability distributions. After that uniformly distributed random numbers are generated and Monte Carlo simulation is performed for possibility distribution to obtain random numbers which gives closed interval and thereafter random numbers and close intervals are assigned in the model. This gives close intervals and we performed arithmetic of intervals using Ganesan interval arithmetic [14]. The process is repeated $\mathrm{N}$ times and cumulative probability distribution for initial and final values are plotted. Using our proposed hybrid method, we have demonstrated a hypothetical case study by 
considering three scenarios. Also we have compared the results obtained by applying vertex method to combine intervals in the proposed hybrid method instead of Ganesan interval arithmetic. Our proposed method comparatively gives better result.

8. ACKNOWLEDGEMENThe work done in this paper is under a research project funded by Board of Research in Nuclear Sciences, Department of Atomic Energy, Govt. of India.

\section{REFERENCES}

[1] A. Bardossy, A. Bronstert A, B Merz , 1-, 2- and 3dimensional modelling of groundwater movement in the unsaturated soil matrix using a fuzzy approach, Adv. Water Resources, 18 (1995) 237-251.

[2] C Baudrit, D. Dubois, H. Fargier, Propagation of Uncertainty involving Imprecision and Randomness. Proc.3d European Conference on Fuzzy Logic and Technology, Zittau (Germany), (2003) 653-658.

[3] C. Baudrit, D. Dubois, H. Fargier, Joint treatment of imprecision and randomness in uncertainty propagation, In:Modern Information Processing: From Theory to Applications. B. Bouchon-Meunier, G. Coletti, R.R. Yager (Eds.), Elsevier, (2006) 37-47.

[4] C. Baudrit, D. Dubois, Comparing Methods for Joint Objective and Subjective Uncertainty Propagation with an example in a risk assessment, Fourth International Symposium on Imprecise Probabilities and Their Application (ISIPTA'05), Pittsburg (USA, Pennsylvanie), (2005) 31-40.

[5] C. Baudrit, D. Dubois, D. Guyonnet, H. Fargier, Joint Treatment of imprecision and Randomness in Uncertainty Propagation, Proc. Conf. on Information Processing and Management of Uncertainty in Knowledge-Based Systems, Perugia, (2004) 873-880.

[6] C. Baudrit, D. Dubois, D. Guyonnet, Joint Propagation and Exploitation of Probabilistic and Possibilistic Information in Risk Assessment, IEEE Transaction on Fuzzy Systems, 14 (2006) 593-608.

[7] C. Dou, W. Woldt, I. Bogardi, M. Dahab, Steady-state groundwater flow simulation with imprecise parameters, Water Resource Res., 31 (1995) 2709-2719.

[8] D. Guyonnet, B. Bourgine, D. Dubois, H. Fargier, B. Côme, J. P. Chilès, Hybrid approach for addressing uncertainty in risk assessments, Journal of Environmental Engineering, 126 (2003) 68-78.
[9] D. Guyonnet, B. Côme, P. Perrochet, A. Parriaux, Comparing two methods for addressing uncertainty in risk assessments, Journal of Environmental Engineering, 125(1999) 660-666.

[10] E.Kentel, M. M. Aral, Probalistic-fuzzy health risk modeling, Stoch Envir Res and Risk Ass 18(2004) 324338.[14]

[11] EPA US. 2001. Risk Assessment Guidance for Superfund, Volume I: Human Health Evaluation Manual (Part E, Supplemental Guidance for Dermal Risk Assessment). Office of Emergency and Remedial Response, EPA/540/R/99/005, Interim, Review Draft. United States Environmental Protection Agency. September 2001.

[12]H. W. Ma, K. Y. Wu, C. D. Ton, Setting information priorities for remediation decisions at a contaminatedgroundwater site, Chemosphere 46 (2002) 75-81.

[13] H. W. Ma, Stochastic multimedia risk assessment for a site with contaminated groundwater, Stochastic Environ Res Risk Assess 16 (2002) 464-478.

[14] K. Ganesan, P. Veeramani, on Arithmetic operations of interval numbers, International journal of uncertainly and knowledge based systems, 13 (2005) 619-631.

[15]P. Labieniec , D. Dzombak, R. Siegrist, Evaluation of uncertainty in a site-specific risk assessment, J. Environ. Eng., 123(1997) 234-243.

[16] P. Prado D. Draper, S. Saltelli, A. Pereira, B. Mendes, S. Eguilior, R. Cheal, S. Tarantola, Gesamac: Conceptual and computational tools to tackle the long-term risk from nuclear waste disposal in the geosphere, in Eur. Commission Rep. EUR 19113 EN: Office for Official Publications of the European Communities, Luxemburg, 1999, vol. 87

[17]R. M. Maxwell, S.D. Pelmulder, A. F. B. Tompson, W. E. Kastenberg, On the development of a new methodology for groundwater-driven health risk assessment, Water Resources Res, 34(1998) 833-847.

[18] R. M. Maxwell, W. E. Kastenberg, Stochastic environmental risk analysis: an integrated methodology for predicting cancer risk from contaminated groundwater, Stochastic Environ Res Risk Assess 13 (1999) 27-47. 